\title{
Warthin-like Mucoepidermoid Carcinoma of the Parotid Gland: Unusual Morphology and Diagnostic Pitfalls
}

\author{
DONGWEI ZHANG ${ }^{1,2}$, XIAOYAN LIAO $^{1}$, YAOYUN TANG ${ }^{2}$, REID G. MEYER ${ }^{3}$, \\ DANIEL L. VAN DYKE ${ }^{3}$, XIULI LIU ${ }^{2}$, MOHAMMED N. ISLAM ${ }^{4}$ and JINPING LAI ${ }^{2,5}$ \\ ${ }^{1}$ Department of Pathology and Laboratory Medicine, University of Rochester Medical Center, Rochester, NY, U.S.A.; \\ ${ }^{2}$ Department of Pathology, Immunology and Laboratory Medicine, \\ University of Florida College of Medicine, Gainesville, FL, U.S.A; \\ ${ }^{3}$ Department of Pathology and Laboratory Medicine, Mayo Clinic, Rochester, MN, U.S.A; \\ ${ }^{4}$ Department of Oral and Maxillofacial Diagnostic Sciences, \\ University of Florida College of Dentistry, Gainesville, FL, U.S.A; \\ ${ }^{5}$ Department of Pathology and Laboratory Medicine, \\ Kaiser Permanente Sacramento Medical Center, Sacramento, CA, U.S.A.
}

\begin{abstract}
Background: Warthin-like mucoepidermoid carcinoma is a newly recognized rare entity and could be misdiagnosed as a benign Warthin tumor. We report such a case of a 36-year-old male who presented with a left parotid gland mass. Case Report: Fine-needle aspiration showed features suggestive of Warthin tumor. Following parotidectomy, grossly there was a $1.6 \mathrm{~cm}$ wellcircumscribed multilobular mass with focal areas of cystic change. Microscopically, at low magnification it had histological features resembling Warthin tumor, while lining with squamoid cells with scattered mucocytes demonstrating mild cytologic atypia was observed at high magnification. Immunohistochemically, the tumor cells were positive for p40, p63, cytokeratin 5/6, cytokeratin 7, and cancer antigen 125, but negative for discovered on GIST-1 (DOG1). Mucicarmine stain highlighted intracellular mucin within mucocytes. Rearrangement of mastermind like transcriptional coactivator 2 (MAML2) (11q21) gene was shown to be present in tumor cells by fluorescence in situ hybridization, supporting the diagnosis of a low-grade Warthin-like mucoepidermoid carcinoma. The patient was disease-free 12 months after surgery. Conclusion: Warthinlike mucoepidermoid carcinoma has not been widely recognized and can be misdiagnosed as Warthin tumor.
\end{abstract}

Correspondence to: Jinping Lai, MD, Ph.D., Department of Pathology and Laboratory Medicine, Kaiser Permanente Sacramento Medical Center, Sacramento, CA, U.S.A. Tel: +1 9169737260, Fax: +1 9169737283, e-mail: jinping.x.lai@kp.org

Key Words: Mucoepidermoid carcinoma, Warthin tumor, fluorescence in situ hybridization, MAML2.
Testing for MAML2 rearrangement provides essential support for diagnosis in difficult cases.

Mucoepidermoid carcinoma (MEC) is the most common malignant neoplasm of salivary gland origin, accounting for approximately $15 \%$ of all salivary gland tumors and $30 \%$ of malignancies (1). The most common site of MEC is the parotid gland, followed by the palate, submandibular gland, and other intraoral minor salivary glands. MEC has a distinctive histological feature composed of squamoid, intermediate and mucinous tumor cells with solid and cystic growth patterns (2-5). The prognosis of MEC correlates with tumor stage and histological grade. Low- and intermediategrade MECs are less aggressive and are generally cured by complete surgical excision (6-8).

There are several relatively uncommon histological variants of MEC, including oncocytic, clear-cell, and sclerosing variants (9-12). At least $60 \%$ of MECs are characterized by a $\mathrm{t}(11 ; 19)(\mathrm{q} 21 ; \mathrm{p} 13)$ translocation and CREB-regulated transcription coactivator 1 (CRTC1)mastermind-like transcriptional coactivator 2 (MAML2) gene fusion $(13,14) . \mathrm{t}(11 ; 15)(\mathrm{q} 21 ; \mathrm{q} 26)$ translocation and CRTC3MAML2 gene fusion is seen in at least $5 \%$ of MEC (15). Warthin-like variant of MEC is a rare newly recognized entity (16). We report a new case, review the literature and discuss its rarity, diagnostic pitfalls, and prognosis.

\section{Case Report}

A 36-year-old non-smoking American male with no significant past medical history noticed a painless lump on the left side of his face 3 months earlier incidentally while shaving. Computerized tomographic (CT) scan showed a $1.6 \mathrm{~cm}$ 

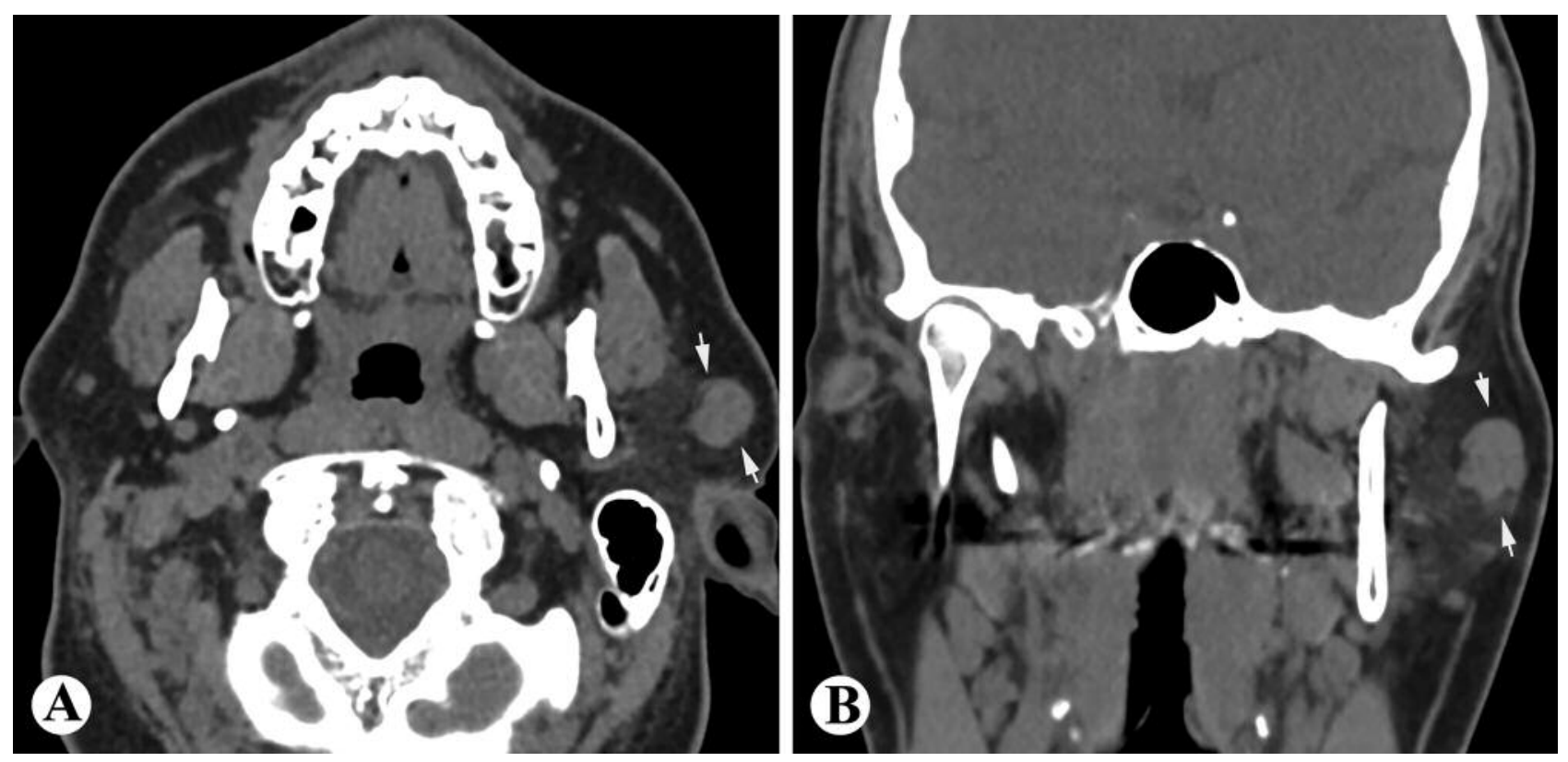

Figure 1. Radiological finding of the left parotid gland mass. Computed tomographic scan showing a 1.6-cm hypodense mass in the left parotid gland lateral to the facial nerve (arrows). A: Axial view. B: Coronal view.

Table I. Summary of reported Warthin-like mucoepidermoid carcinomas including the current case

\begin{tabular}{|c|c|c|c|c|c|c|}
\hline Author & Cases, $\mathrm{n}$ & Age, years & Gender & Tumor size (mm) & $M A M L 2$ rearrangement & Follow-up, years \\
\hline Ishibashi et al. (16) & 5 & $39(28-60)^{*}$ & All female & $28(14-40)^{*}$ & All + & $6.4(1-10)^{*}$ \\
\hline Heatley et al. (18) & 1 & 17 & Female & N/A & ND & $\begin{array}{c}4 \\
\text { Recurrence }\end{array}$ \\
\hline Bishop et al. (19) & 6 & $47(33-53)^{*}$ & $\begin{array}{l}4 \text { Female } \\
2 \text { Male }\end{array}$ & $27(12-33)^{*}$ & All + & $0.5,1$ ( 2 cases $)$ \\
\hline Akaev et al. (20) & 1 & 53 & Female & 9 & + & 1 \\
\hline Current case & 1 & 36 & Male & 16 & + & 1 \\
\hline
\end{tabular}

*Mean (range). ND: Not done.

hypodense nodule in the left parotid gland which was lateral to the facial nerve (Figure 1). Fine-needle aspiration of the mass was attempted, which revealed mostly cystic contents, including macrophages and lymphoid cells. Cell block showed rare epithelioid cells with vacuolated cytoplasm. The differential diagnosis included Warthin tumor, or a tumor with sebaceous cell component, among others. No histological evidence of malignancy was noted in this specimen.

One month after the fine-needle aspiration, the patient underwent left parotidectomy. Grossly, a $1.6 \mathrm{~cm}$ wellcircumscribed multilobular mass with focal areas of cystic change was identified. The tumor was heterogeneous in color, with pale pink-tan areas admixed with yellow-orange areas. No necrosis was grossly identified. Microscopically, at low magnification the tumor was composed of multiloculated cystic epithelial proliferation surrounded by a well-circumscribed cuff of prominent lymphoid stroma with germinal centers, typical of Warthin-like tumor. However, at high magnification, some areas of the lining epithelial cells showed features of stratified squamoid cells and mucocytes with mild cytological atypia and focal complex architecture.

No lymphovascular invasion, perineural invasion, or lymph node metastasis was identified. Immunohistochemically, the tumor cells were positive for p40, p63, cytokeratin 5/6, cytokeratin 7, and cancer antigen 125 (CA 125), but negative for discovered on GIST-1 (DOG1). p53 staining showed wildtype expression pattern. Ki-67 highlighted $<2 \%$ of tumor cells. Mucicarmine stain highlighted intracellular mucin within mucocytes (Figure 2). 


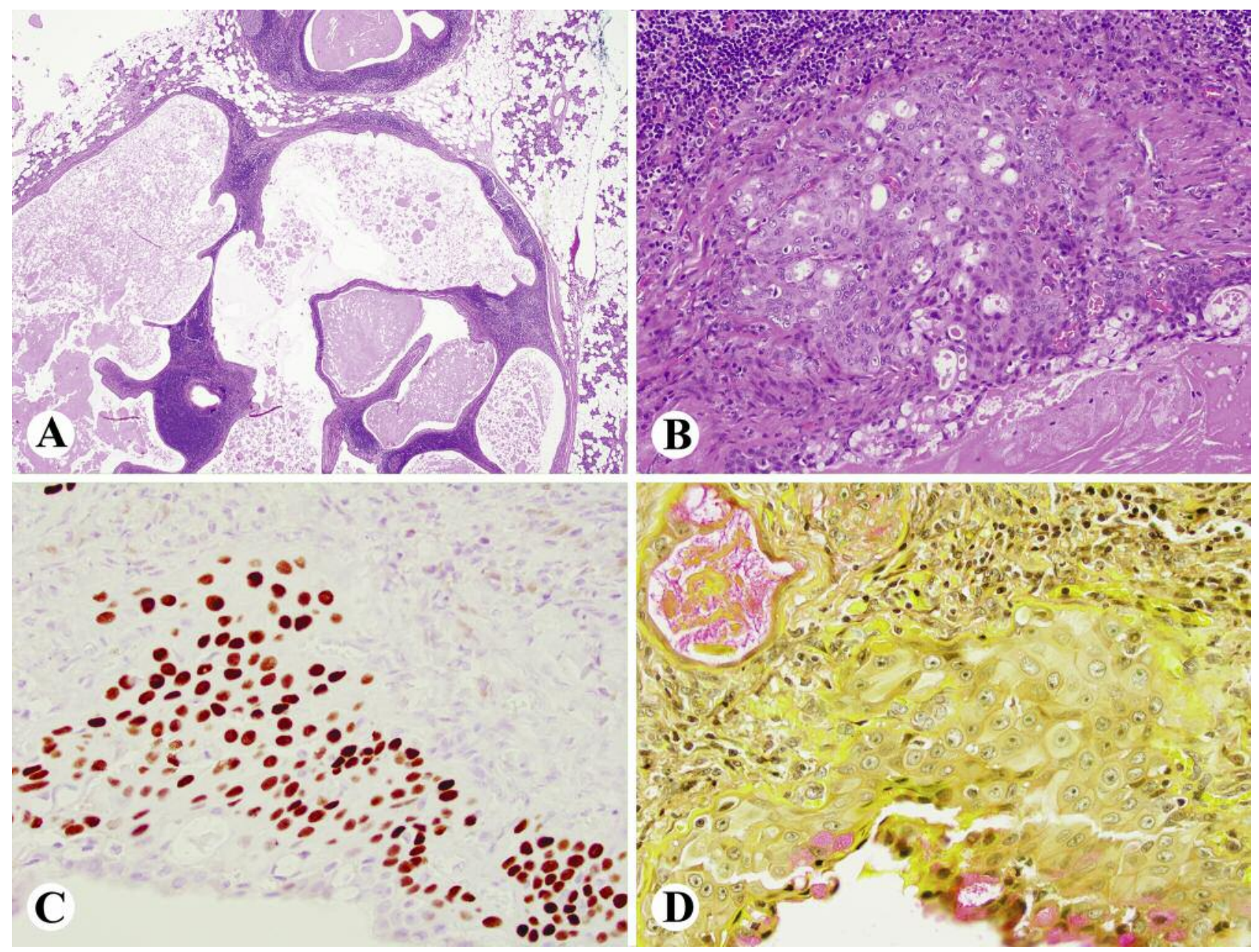

Figure 2. Histological features and ancillary studies of the left parotid gland mass. A: Low-power view of the tumor showing a prominent cystic architecture with lymphoid tissue, suggesting a Warthin tumor-like pattern [hematoxylin and eosin (HE), x20]. B: High-power magnification showing squamoid cells and some mucocytes focally present in the tumor $(H \& E, \times 200)$. C: The tumor cells were positive for p40 by immunohistochemistry (×400). D: Mucicarmine stain highlighted the mucocytes $(\times 400)$.

To further classify the tumor type, fluorescence in situ hybridization (FISH) testing for MAML2 (11q21) rearrangement was performed using a laboratory-developed MAML2 (11q21) dual-color break-apart strategy probe. MAML2 rearrangement was identified in the tumor cells by FISH (Figure 3).

Overall, the histological features, immunoprofile and FISH for MAML2 rearrangement supported the diagnosis of low-grade Warthin-like MEC, American Joint Committee of Cancer (8th edition) pathologic stage pT1N0 (17). The patient recovered well. He remains disease-free 12 months post-operatively.

\section{Discussion}

Warthin-like MEC is a newly recognized entity. Ishibashi $e t$ al. firstly described this entity by analyzing 15 tumors originally diagnosed as metaplastic Warthin tumors. They found that five of those "metaplastic Warthin-like" tumors in their series were positive for CRTC1-MAML2 gene fusions, suggesting that the term 'Warthin-like' should be considered as a variant of MEC (16). Since then, fewer than 20 cases of Warthin-like MEC were described in the literature and these are summarized in Table I (16, 18-20). All of the reported Warthin-like MECs were located in the parotid gland. The mean age of the patients was 42 years (range $=17$ to 60 years). A definite female predominance is noted (5.5:1 female to male ratio). Follow-up studies showed that all of the patients were alive after a mean follow-up of 4.2 years (range $=0.5$ to 10 years). Tumor recurrence was only detected in one case in a 17-year-old female and the recurrent tumor showed a strikingly different architectural pattern when compared with the original neoplasm, with prominent areas exhibiting a 


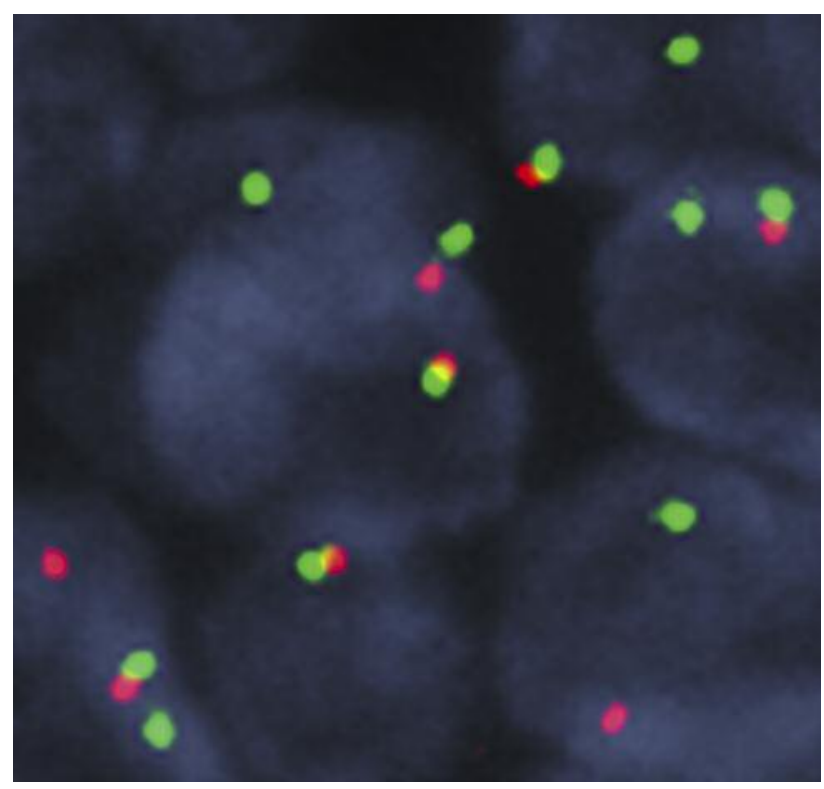

Figure 3. Fluorescence in situ hybridization showing mastermind-like transcriptional coactivator 2 (MAML2) (11q21) rearrangement in the tumor cells.

classical mucoepidermoid morphology (18). Warthin-like MEC is considered a low-grade malignancy at an early stage. Complete excision is considered the major treatment strategy. In the MEC cases which show Warthin-like features, detection of a MAML2 rearrangement is considered a diagnostic gold standard, and can help avoid confusion with a true Warthin tumor showing mucinous and squamous metaplasia.

The main differential diagnosis of Warthin-like MEC includes Warthin tumor with mucinous and squamous metaplasia (metaplastic Warthin tumors) or lymphoepithelial cyst. When compared with typical Warthin tumors with classic oncocytic bilayered epithelium, Warthin-like MECs showed a variety of histological changes in the epithelium, including the presence of goblet cells and squamoid cells. The bilayered epithelium was apparent but was often less tall and less oncocytic than typical Warthin tumor. The presence of typical bilayered epithelium was considered to be the most useful distinguishing morphological feature. Most importantly, all metaplastic Warthin tumors are negative for $M A M L 2$ gene fusions.

In conclusion, we report a case of Warthin-like variant of MEC, a rare newly recognized entity. When squamoid and mucocytes are present in a Warthin-like tumor with atypical oncocytic bilayered epithelium, a diagnosis of Warthin-like MEC should be considered. Detecting MAML2 rearrangement by FISH study should be performed to confirm the diagnosis of MEC. Awareness of this entity is crucial, as patients could potentially be inappropriately discharged without follow-up if mistakenly diagnosed with a benign Warthin tumor. On the other hand, this type of tumor is considered low grade, with good prognosis, and therefore, overtly aggressive treatment should be avoided.

\section{Conflicts of Interest}

The Authors have no conflicts of interest to declare.

\section{Authors' Contributions}

D.Z. and J.L. contributed to the design and implementation of the study, to the analysis of the results and to the writing of the article. R.M. and D.V. performed the MAML2 FISH test and interpreted the result. X.L. (Xiaoyan Liao), Y.T., M.I., and X.L. (Xiuli Liu) contributed to the writing of the article.

\section{References}

1 Spiro RH, Huvos AG, Berk R and Strong EW: Mucoepidermoid carcinoma of salivary gland origin: a clinicopathologic study of 367 cases. Am J Sur 136: 461-468, 1978. PMID: 707726.

2 Brandwein-Gensler M, Bell D, Inagaki H, Katabi N, Leivo I, Seethala R and Triantafyllou A: Mucoepidermoid carcinoma. In: World Health Organization Classification of Head and Neck Tumours. El-Naggar AK, Chan JKC, Grandis JR, Takata T and Slootweg PJ (eds.). IARC Press, Lyon, pp. 163-164, 2017.

3 Coca-Pelaz A, Rodrigo JP, Triantafyllou A, Hunt JL, Rinaldo A, Strojan P, Haigentz M Jr., Mendenhall WM, Takes RP, Vander Poorten V and Ferlito A: Salivary mucoepidermoid carcinoma revisited. Eur Arch Otorhinolaryngol 272: 799-819, 2015. PMID: 24771140. DOI: 10.1007/s00405-014-3053-z

4 Bai S, Clubwala R, Adler E, Sarta C, Schiff B, Smith RV, Gnepp DR and Brandwein-Gensler M: Salivary mucoepidermoid carcinoma: a multi-institutional review of 76 patients. Head Neck Pathol 7: 105-112, 2013. PMID: 23080318. DOI: 10.1007/ s12105-012-0405-0

5 Brandwein MS, Ivanov K, Wallace DI, Hille JJ, Wang B, Fahmy A, Bodian C, Urken ML, Gnepp DR, Huvos A, Lumerman H and Mills SE: Mucoepidermoid carcinoma: a clinicopathologic study of 80 patients with special reference to histological grading. Am J Surg Pathol 25: 835-845, 2001. PMID: 11420454.

6 Goode RK, Auclair PL and Ellis GL: Mucoepidermoid carcinoma of the major salivary glands: Clinical and histopathologic analysis of 234 cases with evaluation of grading criteria. Cancer 82: 1217-1224, 1998. PMID: 9529011.

7 Pires FR, de Almeida OP, de Araújo VC and Kowalski LP: Prognostic factors in head and neck mucoepidermoid carcinoma. Arch Otolaryngol Head Neck Surg 130: 174-180, 2004. PMID: 14967746.

8 Katabi N, Ghossein R, Ali S, Dogan S, Klimstra D and Ganly I: Prognostic features in mucoepidermoid carcinoma of major salivary glands with emphasis on tumour histologic grading. Histopathology 65: 793-804, 2014. PMID: 25040772. DOI: 10.1111/his.12488

9 Weinreb I, Seethala RR, Perez-Ordoñez B, Chetty R, Hoschar AP and Hunt JL: Oncocytic mucoepidermoid carcinoma: Clinicopathological description in a series of 12 cases. Am J Surg Pathol 33: 409-416, 2009. PMID: 18971778. DOI: 10.1097/PAS.0b013e318184b36d. 
10 Liao X, Haghighi P, Coffey CS and Xu X: Rare case of exclusively oncocytic mucoepidermoid carcinoma with MAML2 translocation. Rare Tumors 8: 6166, 2016. PMID: 27441073. DOI: $10.4081 / \mathrm{rt} .2016 .6166$

11 Ide F, Mishima K and Saito I: Mucoepidermoid carcinoma with spindle cell change: a low grade lesion potentially mistaken for sarcomatoid dedifferentiation. Head Neck Pathol 2: 227-230, 2008. PMID: 20614320. DOI: 10.1007/s12105-008-0067-0

12 Tian W, Yakirevich E, Matoso A and Gnepp DR: IgG4+ plasma cells in sclerosing variant of mucoepidermoid carcinoma: A new and evolving concept. Am J Surg Pathol 36: 973-979, 2012. PMID: 22743285. DOI: 10.1097/PAS.0b013e318258f018

13 Seethala RR, Dacic S, Cieply K, Kelly LM, Nikiforova MN: A reappraisal of the MECT1/MAML2 translocation in salivary mucoepidermoid carcinomas. Am J Surg Pathol 34: 1106-1121, 2010. PMID: 20588178. DOI: 10.1097/PAS.0b013e3181de3021

14 Jee KJ, Persson M, Heikinheimo K, Passador-Santos F, Aro K, Knuutila S, Odell EW, Mäkitie A, Sundelin K, Stenman G and Leivo I: Genomic profiles and CRTC1-MAML2 fusion distinguish different subtypes of mucoepidermoid carcinoma Mod Pathol 26: 213-222, 2013. PMID: 23018873. DOI: 10.1038/modpathol.2012.154.

15 Nakayama T, Miyabe S, Okabe M, Sakuma H, Ijichi K, Hasegawa Y, Nagatsuka H, Shimozato K and Inagaki H: Clinicopathological significance of the CRTC3-MAML2 fusion transcript in mucoepidermoid carcinoma. Mod Pathol 22: 1575-1581, 2009. PMID: 19749740. DOI: 10.1038/modpathol. 2009.126

16 Ishibashi K, Ito Y, Masaki A, Fujii K, Beppu S, Sakakibara T, Takino H, Takase H, Ijichi K, Shimozato K and Inagaki H: Warthin-like mucoepidermoid carcinoma: a combined study of fluorescence in situ hybridization and whole-slide imaging. Am J Surg Pathol 39: 1479-1487, 2015. PMID: 26457352. DOI: 10.1097/PAS.0000000000000507
17 Lydiatt WM, Mukherji SK, O'Sullivan B, Patel SG and Shah JP: Major salivary glands. In: AJCC Cancer Staging Manual (Eighth Edition). Amin MB (ed.). Springer Publishing, New York, pp. 95-101, 2017.

18 Heatley N, Harrington KJ and Thway K: Warthin tumor-like mucoepidermoid carcinoma. Int J Surg Pathol 26: 31-33, 2018. PMID: 28793830. DOI: 10.1177/1066896917724889

19 Bishop JA, Cowan ML, Shum CH and Westra WH: MAML2 rearrangements in variant forms of mucoepidermoid carcinoma: Ancillary diagnostic testing for the ciliated and Warthin-like variants. Am J Surg Pathol 42: 130-136, 2018. PMID: 28877061. DOI: 10.1097/PAS.0000000000000932

20 Akaev I, Yeoh CC, Brennan PA and Rahimi S: Low-grade parotid mucoepidermoid carcinoma with tumour-associated lymphoid proliferation ('Warthin-like') and CRTC1-MAML2 fusion transcript: Definitive diagnosis with molecular investigation only. Oral Oncol 80: 98-99, 2018. PMID: 29571603. DOI: 10.1016/j.oraloncology.2018.03.010
Received May 7, 2019

Revised May 14, 2019

Accepted May 17, 2019 